\title{
A Simplified Extractive Metallurgy Exercise to Demonstrate Selective Extraction of Copper
}

Iain A. Smellie, * Yusra Abdelhamid, Cameron L. Carpenter-Warren, David B. Cordes, Clement Elliott,

5 Sarah Lamorte, Iain. L. J. Patterson, William Sanders, Iain P. Sandison, Alexandra M. Z. Slawin, Dominic M. Stewart, Samuel N. Walters.

*EaStChem, University of St Andrews, School of Chemistry, St Andrews, Fife, KY16 9ST, Scotland, United Kingdom.

\section{ABSTRACT}

A laboratory activity is described for senior high school or $1^{\text {st }}$ year undergraduate level students that illustrates key concepts linked to extractive metallurgy. This experiment demonstrates preferential binding of a methoxyphenolic oxime ligand to $\mathrm{Cu}^{2+}$ in the presence of other transition metal ions in aqueous solution. The students are tasked to investigate the importance of the spatial relationship between the oxime and phenol group of two potential ligands by performing a series of short and simple tests. The objective is achieved by identifying which methoxyphenolic oxime ligand selectively and rapidly forms an isolable precipitate with $\mathrm{Cu}^{2+}$ ions. Only one of the potential ligands exhibits a clear preference for binding to $\mathrm{Cu}^{2+}$ and this can easily be identified visually (and confirmed by UVvisible spectroscopy if desired). The experiment has successfully been employed as part of an extracurricular laboratory course involving groups of 25-30 high school students.
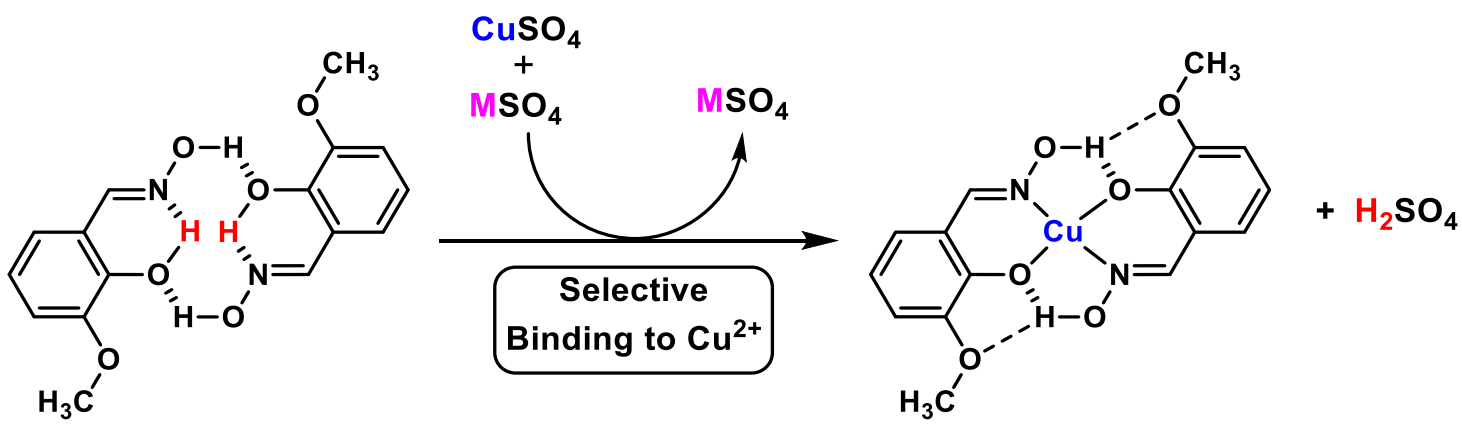

\section{KEYWORDS}

High School / Introductory Chemistry, First-Year Undergraduate / General, Interdisciplinary / Multidisciplinary, Laboratory Instruction, Hands-On Learning / Manipulatives, Problem Solving / 
Decision Making, Applications of Chemistry, Coordination Compounds, Metallurgy, Qualitative Analysis, UV-Vis Spectroscopy

\section{INTRODUCTION}

For several years we have successfully implemented an advanced level interdisciplinary laboratory activity that models industrial hydrometallurgical extraction of copper. ${ }^{1}$ In that exercise, the students are tasked to prepare phenolic oximes as copper extractants and then spectroscopically determine whether the oxime they have prepared can be used to selectively extract $\mathrm{Cu}^{2+}$ in the presence of $\mathrm{Ni}^{2+}$ (scheme 1). As well as being a useful model of an economically important process, ${ }^{2}$ this particular exercise has proved to be very adaptable for use in short open-ended projects where the students can prepare and screen a variety of phenolic oximes as potential extractants. Earlier studies had shown that 5-(tert-butyl)-2-hydroxybenzaldehyde oxime (1 illustrated as a hydrogen bonded dimer) was one of the best extractants in terms of ease of preparation, selectivity for $\mathrm{Cu}^{2+}$ and solubility in hydrocarbon solvents.

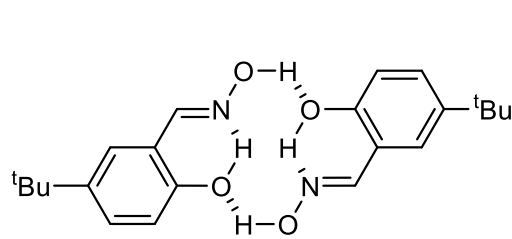

1
$\mathrm{CuSO}_{4}+\mathrm{NiSO}_{4}$

30 minutes mixing

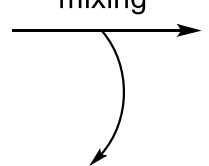

$\mathrm{NiSO}_{4}$

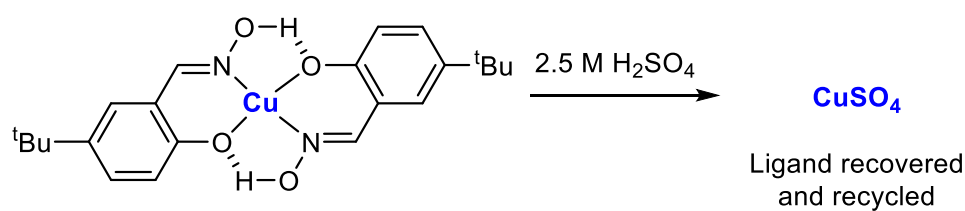
and recycled

40

Scheme 1 - Selective extraction of $\mathrm{Cu}^{2+}$ ions by 5-(tert-butyl)-2-hydroxybenzaldehyde oxime (1)

Our subsequent work has found that many other candidate phenolic oximes were easily prepared by the students and these could be shown to be highly selective for $\mathrm{Cu}^{2+}$ ions. However, these compounds were found to be inferior extractants due to the resulting copper complexes having very poor solubility in hydrocarbon solvents. These results were initially disappointing, although it was soon realised that these observations could form the basis of a new experiment aimed at showing selective binding to $\mathrm{Cu}^{2+}$ ions, but in a simpler way. It was envisaged that such an activity would be suitable for students at a less advanced stage of study. The revised objective was to implement a 
transition metal ions and demonstrate: 1) that certain structural motifs promote complexation to transition metal ions and 2) that it is possible to selectively bind to copper ions (an observed insoluble complex would only form with $\mathrm{Cu}^{2+}$ ) in the presence of other transition metal ions.

\section{PEDAGOGICAL GOALS}

In this paper we report a simplified derivative of our original extractive metallurgy exercise, ${ }^{1}$ in this case the activity is aimed at high school students or those in the early years of study at University. The pedagogical goals of this work are as follows:

- To help develop skills in systematic testing, careful observations and note taking.

- To provide an opportunity to test a simple hypothesis and demonstrate the importance of control experiments in drawing conclusions from experimental evidence,

- To use a scenario-based format to provide a "real-world" context for a practical activity.

\section{EXPERIMENTAL OVERVIEW}

As described in our earlier study, ${ }^{1}$ phenolic oximes, salicylaldoxime derivatives in particular, serve as efficient extractants for $\mathrm{Cu}^{2+}$ ions. The observed selectivity of these compounds for copper is attributed to their ability to form pre-organised hydrogen-bound dimers in solution, this arrangement affords a 14-membered pseudomacrocycle that is selective for $\mathrm{Cu}^{2+}$ at low $\mathrm{pH} .{ }^{2}$ This process has been extensively studied in the context of industrial extraction, however, the selectivity for various metals by varying $\mathrm{pH}$ has been known for a longer period of time. Indeed, the oxime derivative of salicylaldehyde (salicylaldoxime) was studied in the early $20^{\text {th }}$ century and exploited for gravimetric analysis prior to the introduction of more modern analytical techniques. ${ }^{3-6}$ In this study, we found that methoxyphenolic oxime $\mathbf{2}$ was particularly effective since the resulting copper complex (3) formed very quickly, and readily precipitated from the resulting acidic solution (sulfuric acid is released as binding of the methoxyphenolic oxime to $\mathrm{Cu}^{2+}$ proceeds). Complexation of methoxyphenolic oxime 2 with copper ions has been the subject of research in recent years, most notably by MAS-NMR spectroscopy ${ }^{7}$ and single-crystal X-ray diffraction. ${ }^{8}$ As part of our study, we were able to obtain our own diffraction data for complex 3 (see figure 1 and the CIF file in the supporting information) and this proved to be very useful as an instructional tool for the activity described herein. In addition to the favourable 
selectivity and structural properties, methoxyphenolic oxime $\mathbf{2}$ is also readily prepared from a commercially available and inexpensive isomer of vanillin (scheme 2 - synthetic procedures are outlined in the supporting information).<smiles>COc1cccc(/C=N/O)c1O</smiles>

2

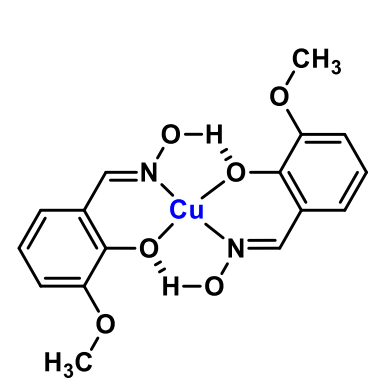

3

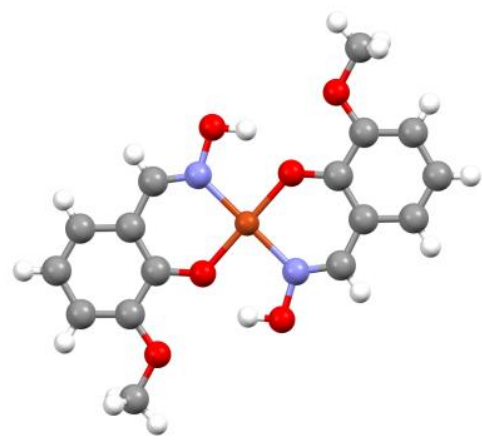

3

Figure 1 - (left) schematic representation of methoxyphenolic oxime 2, (middle) schematic representation of copper complex 3, and (right) Xray crystal structure of copper complex $\mathbf{3}$.

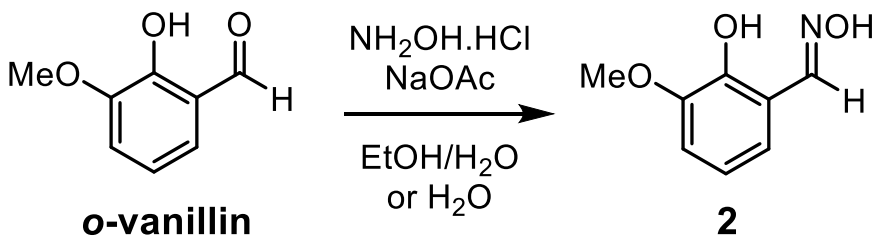<smiles>CCOC(=O)C[C@H](ON)[C@H](ON)ONCc1ccc(O)cc1OC</smiles>

vanillin<smiles>COc1cc(O)ccc1C=O</smiles>

Scheme 2 - Preparation of $o$-vanillin-derived oxime 2 and vanillin-derived oxime 4.

Initial testing focused on additions of $1 \%(\mathrm{w} / \mathrm{v})$ solutions of oxime 2 in ethanol to $0.1 \mathrm{M}$ aqueous solutions of $\mathrm{CuSO}_{4}, \mathrm{NiSO}_{4}, \mathrm{CoSO}_{4}$ and $\mathrm{ZnSO}_{4}$. It was observed that with gentle agitation, precipitates formed within a few seconds in the solutions containing $\mathrm{Cu}^{2+}$ and $\mathrm{Ni}^{2+}$ ions. However, precipitates did not form at all in the solutions containing $\mathrm{Co}^{2+}$ and $\mathrm{Zn}^{2+}$, even after agitation of these solutions over a period of several minutes. Pleasingly, addition of oxime 2 to a $1: 1$ mixture of $\mathrm{CuSO}_{4}$ and $\mathrm{NiSO}_{4}$, preferentially formed the corresponding copper complex (3). Further investigations established that the concentration of the oxime solutions could be reduced to $0.5 \%(\mathrm{w} / \mathrm{v})$ without any negative impact on the quality of the test observations. The experimental set up was designed to be 
simple so the need for large quantities of specialist glassware was reduced as much as possible. Standard 10-20 mL test tubes were found to be satisfactory for observing the reactions and the precipitates were easily isolated by filtration through fluted filter paper or by vacuum filtration with a Hirsch funnel.

One of the aims of the experiment was to provide an option for the students to test a hypothesis. In this case, we chose to focus on the structure of the oxime ligand, and ask if there was a specific requirement to have an oxime and phenol group or an oxime and an alternative functional group adjacent to each other. In order to demonstrate the importance of the ortho relationship between the oxime and phenol group, an isomeric oxime ligand that would be unlikely to bind strongly to the metal ions was required. We found oxime 4 convenient for this purpose since the phenol and oxime groups are para to each other. Satisfyingly, as expected, mixing ethanolic solutions of oxime 4 with $0.1 \mathrm{M}$ aqueous solutions of $\mathrm{CuSO}_{4}, \mathrm{NiSO}_{4}, \mathrm{CoSO}_{4}$ and $\mathrm{ZnSO}_{4}$ showed that no precipitates were formed. Oxime 4, was also found to be easily prepared from readily commercially available and inexpensive vanillin using the same procedures as oxime 2 (scheme 2 - the synthetic procedures are outlined in the supporting information). A further objective was to demonstrate the use of a control, since this activity focused on observing precipitation of a metal complex, it was essential to ensure that both oximes were completely soluble in the test solutions. To ensure no false positive results could be obtained, ethanol solutions of each of the oximes were added to $2 \mathrm{~mL}$ portions of water and dilute sulfuric acid. In all cases, precipitates were not observed so both oximes were found to be suitable for the required tests with transition metal ions.

Although the colour of the precipitated metal complexes would be useful indicators of successful binding, we desired an option for further evidence to be readily acquired. Fortunately, our earlier studies ${ }^{1}$ had found UV-visible spectroscopy to be a quick and effective way of identifying phenolic oxime complexes of copper, and we again found UV-visible spectroscopy allowed straightforward identification of the copper complex in dimethyl sulfoxide (DMSO) solution.

\section{HAZARDS}


A laboratory coat and safety glasses must be worn at all times. Do not allow any of the substances in use to come into contact with skin or eyes. Ethanol is flammable and harmful by inhalation, ingestion or skin absorption. Care must be taken to avoid inhaling transition metal dusts during weighing operations. Dusts of nickel and cobalt compounds are particularly hazardous since they are potentially carcinogenic and can cause skin allergy in some individuals. For these reasons, it is suggested that the students should not prepare the transition metal solutions themselves, this task should instead be completed by laboratory technicians in advance of the laboratory class. All transition metal wastes should be considered as toxic in an aquatic environment and should be collected in appropriate containers for disposal according to local regulations. Contact with dimethyl sulfoxide (DMSO) can result in skin irritation and absorption of the solvent (and the solute) through the skin, therefore appropriate disposable gloves should be worn.

\section{RESULTS AND DISCUSSION}

Groups of 30 senior level high school students were divided into pairs and each pair was provided with a set of test tubes, vacuum filtration equipment and had access to a UV-visible spectrometer. As part of the experimental introduction, the students were made aware of the two possible methoxyphenolic oxime structures, this allowed them to have a short discussion about ligand binding with an instructor and then try to predict which oxime might be a better ligand. While conducting the experiment, the students worked with solutions labelled "oxime A" and "oxime B", once the results of all the tests were complete, the identities of oximes A and B were revealed. The students unanimously identified oxime $\mathbf{2}$ as the most appropriate, this observation then allowed the importance of the ortho-phenolic oxime group to the $\mathrm{Cu}^{2+}$ binding event to be discussed with laboratory instructors. The crystal structure of the compound proved to be particularly useful as part of the concluding discussions since the relative orientation of the binding groups was very easily recognized from this.

Precipitation tests with methoxyphenolic oxime 2 ("oxime A") with $\mathrm{Co}^{2+}, \mathrm{Ni}^{2+}, \mathrm{Cu}^{2+}$ and $\mathrm{Zn}^{2+}$ solutions 
$2 \mathrm{~mL}$ portions of $0.1 \mathrm{M}$ cobalt(II) sulfate, nickel(II) sulfate, copper(II) sulfate or zinc(II) sulfate were transferred to a test tube and placed in a test tube rack. $1 \mathrm{~mL}$ portions of $0.5 \%(\mathrm{w} / \mathrm{v})$ ethanolic "oxime A" solution were added to each tube, the contents were gently shaken for 20-30 seconds and then each tube was allowed to stand for a 2-3 minutes. The solutions containing $\mathrm{Co}^{2+}$ and $\mathrm{Zn}^{2+}$ showed no change in colour and did not form a precipitate. As expected, the solutions containing $\mathrm{Ni}^{2+}$ and $\mathrm{Cu}^{2+}$ did form precipitates, a green complex deposited from $\mathrm{Ni}^{2+}$ solution and a brown complex rapidly deposited from the $\mathrm{Cu}^{2+}$ solution (all the test results are shown in figure 2).

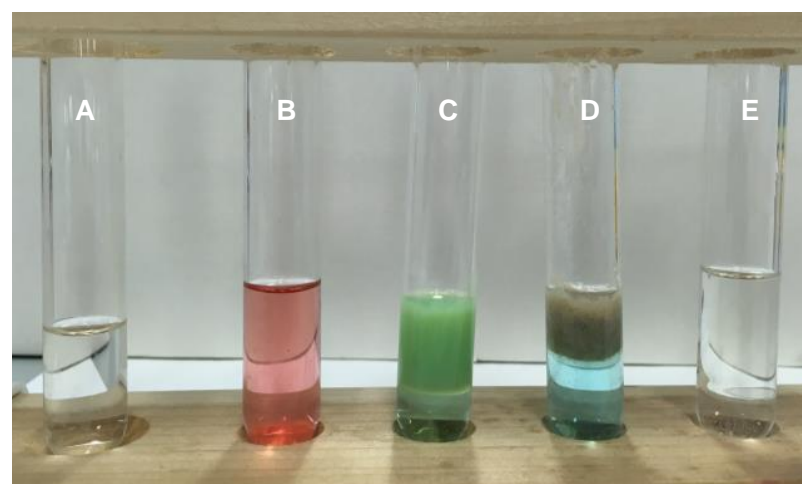

Figure 2 - Test results for methoxyphenolic oxime 2 (control tube A contains a $0.5 \%(\mathrm{w} / \mathrm{v})$ solution of 2 in ethanol). Tubes B-E contain $1 \mathrm{~mL}$ of $0.5 \%(\mathrm{w} / \mathrm{v})$ ethanol solution of 2 mixed with $2 \mathrm{~mL}$ of: $\mathbf{B}=0.1 \mathrm{M} \mathrm{CoSO}_{4}, \mathbf{C}=0.1 \mathrm{M} \mathrm{NiSO}_{4}, \mathbf{D}=0.1 \mathrm{M} \mathrm{CuSO}_{4}, \mathbf{E}=0.1 \mathrm{M} \mathrm{ZnSO}_{4}$.

Precipitation tests with oxime 4 ("oxime B") with $\mathrm{Co}^{2+}, \mathrm{Ni}^{2+}, \mathrm{Cu}^{2+}$ and $\mathrm{Zn}^{2+}$ solutions

$2 \mathrm{~mL}$ portions of $0.1 \mathrm{M}$ cobalt(II) sulfate, nickel(II) sulfate, copper(II) sulfate or zinc(II) sulfate

were transferred to a test tube and placed in a test tube rack. $1 \mathrm{~mL}$ portions of $0.5 \%(\mathrm{w} / \mathrm{v})$ ethanolic "oxime B" solution were added to each tube, the contents were gently shaken for 20-30 seconds and then each tube was allowed to stand for a 2-3 minutes. In this series of tests, none of the solutions showed any sign of precipitation or colour changes (all the test results are shown in figure 3).

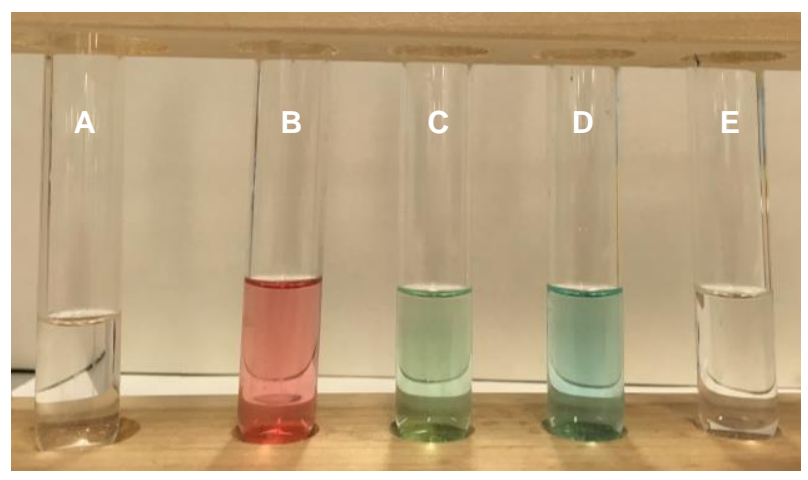


Figure 3 - Test results for oxime 4 (control tube A contains a $0.5 \%(w / v)$ solution of 4 in ethanol). Tubes B-E contain $1 \mathrm{~mL}$ of $0.5 \%(\mathrm{w} / \mathrm{v})$ ethanol solution of 4 mixed with $2 \mathrm{~mL}$ of: $\mathbf{B}=0.1 \mathrm{M} \mathrm{CoSO}_{4}, \mathbf{C}=0.1 \mathrm{M} \mathrm{NiSO}_{4}, \mathbf{D}=0.1 \mathrm{M} \mathrm{CuSO}_{4}, \mathbf{E}=0.1 \mathrm{M} \mathrm{ZnSO}_{4}$.

Tests with methoxyphenolic oxime 2 and oxime 4 with aqueous $\mathrm{Fe}^{3+}$

In a real mining situation, iron(III) containing materials would also be present, so selectivity tests in the presence of $\mathrm{Fe}^{3+}$ are also relevant, $0.1 \mathrm{M}$ ammonium iron(III) sulfate is a readily available source of $\mathrm{Fe}^{3+}$ for this purpose. A $2 \mathrm{~mL}$ portion of $0.1 \mathrm{M}$ ammonium iron(III) sulfate was transferred to a test tube and placed in a test tube rack. Addition of a $1 \mathrm{~mL}$ portion of $0.5 \%(\mathrm{w} / \mathrm{v})$ solution of methoxyphenolic oxime $\mathbf{2}$ in ethanol showed a change in colour (orange to dark purple, test B, figure 4) but a precipitate was not observed. This particular observation frequently prompted discussion with the students since the complex formed with iron results in a very dark solution (in many respects resembling ink) and some people therefore found it more challenging to rapidly establish whether solid material was present or not. However, careful observations revealed that no solid was present. These results are consistent with earlier studies which focused on the use of salicylaldoxime as an agent in quantitative spectrophotometric analysis of $\mathrm{Fe}^{3+}$ solutions. ${ }^{9}$ The original paper suggests at low $\mathrm{pH}$ salicylaldoxime solutions should be dark purple in colour. Addition of a $1 \mathrm{~mL}$ portion of $0.5 \%(\mathrm{w} / \mathrm{v})$ ethanolic oxime 4 did not afford a purple solution or a precipitate, in this case, the solution remained orange but turned slightly darker (Test D, figure 4).

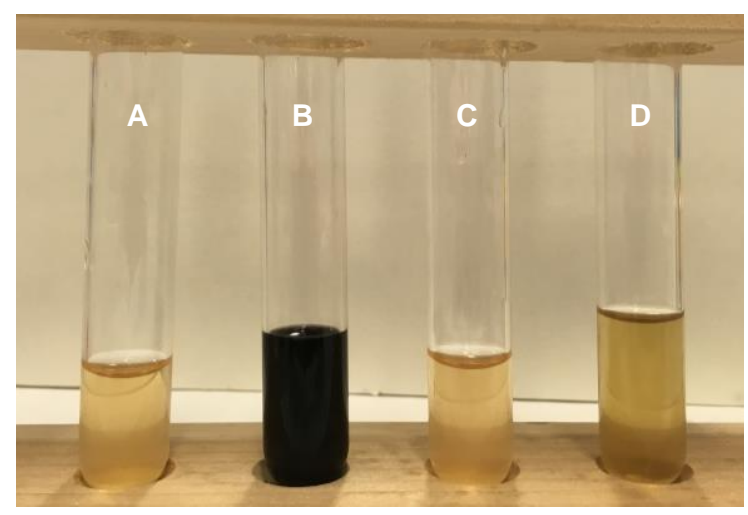

Figure 4 - Test results for oximes $\mathbf{2}$ and $\mathbf{4}$ with $\mathrm{Fe}^{3+}$ (control tube $\mathbf{A}$ contains a $0.5 \%$ (w/v) solution of $\mathbf{2}$ in ethanol, control tube $\mathbf{C}$ contains a $0.5 \%(\mathrm{w} / \mathrm{v})$ solution of 4 in ethanol). Tube B contains $1 \mathrm{~mL}$ of $0.5 \%(\mathrm{w} / \mathrm{v})$ ethanol solution of 2 mixed with $2 \mathrm{~mL}$ of $0.1 \mathrm{M}\left(\mathrm{NH}_{4}\right) \mathrm{Fe}\left(\mathrm{SO}_{4}\right)_{2}$. Tube D contains $1 \mathrm{~mL}$ of $0.5 \%(\mathrm{w} / \mathrm{v})$ ethanol solution of 4 mixed with $2 \mathrm{~mL}$ of $0.1 \mathrm{M}\left(\mathrm{NH}_{4}\right) \mathrm{Fe}\left(\mathrm{SO}_{4}\right)_{2}$.

Tests with methoxyphenolic oxime 2 and mixed metal sulfate solutions 
The initial precipitation tests (figures 2 and 3) showed that-insoluble metal complexes are only formed when methoxyphenolic oxime 2 is added to a solution of $\mathrm{Cu}^{2+}$ or $\mathrm{Ni}^{2+}$. A final test with a $1: 1$ mixture of $\mathrm{CuSO}_{4}$ and $\mathrm{NiSO}_{4}$ resulted in a brown precipitate as the sole product (figure 5 , test $\mathrm{C}$ ), this observation is consistent with the expected selectivity for $\mathrm{Cu}^{2+}$. This expectation was subsequently confirmed after isolation of the copper complex by filtration and analysis using UV-visible spectroscopy. We have also found that a four-component mixture containing $0.1 \mathrm{M}$ solutions of $\mathrm{CuSO}_{4}, \mathrm{NiSO}_{4}, \mathrm{CoSO}_{4}$, and $\mathrm{ZnSO}_{4}$ also affords the copper complex as the sole product (figure 5, test D).

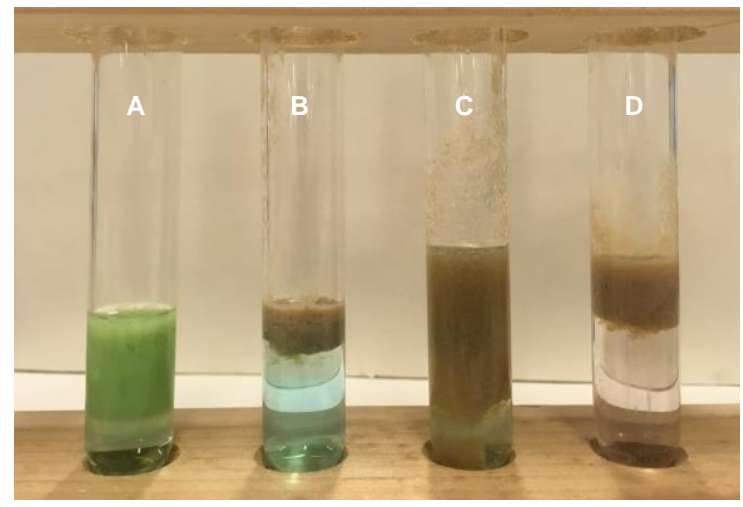

Figure 5 - Test results for oxime 2 with mixed metal sulfate solutions. Tube A contains $1 \mathrm{~mL}$ of $0.5 \%(\mathrm{w} / \mathrm{v})$ ethanol solution of 2 mixed with 2 $\mathrm{mL}$ of $0.1 \mathrm{M} \mathrm{NiSO}_{4}$. Tube B contains $1 \mathrm{~mL}$ of $0.5 \%(\mathrm{w} / \mathrm{v})$ ethanol solution of 2 mixed with $2 \mathrm{~mL}$ of $0.1 \mathrm{M} \mathrm{CuSO}$. Tube $\mathbf{C}$ contains $1 \mathrm{~mL}$ of $0.5 \%$ (w/v) ethanol solution of 2 mixed with $2 \mathrm{~mL}$ of $0.1 \mathrm{M} \mathrm{NiSO}_{4}$ and $2 \mathrm{~mL}$ of $0.1 \mathrm{M} \mathrm{CuSO}_{4}$. Tube $\mathbf{D}$ contains $1 \mathrm{~mL}$ of $0.5 \%$ (w/v) ethanol solution of 2 mixed with $1 \mathrm{~mL}$ of $0.1 \mathrm{M} \mathrm{CoSO}_{4}, 1 \mathrm{~mL}$ of $0.1 \mathrm{M} \mathrm{NiSO}_{4}, 1 \mathrm{~mL}$ of $\mathrm{CuSO}_{4}$, and $1 \mathrm{~mL}$ of $0.1 \mathrm{M} \mathrm{ZnSO} 4$

Copper complex $\mathbf{3}$ was found to be particularly insoluble in the majority of solvents used in teaching laboratories, however, preparation of sample solutions in dimethyl sulfoxide (DMSO) allowed satisfactory UV-vis absorption spectra to be obtained. Our previous study ${ }^{1}$ found that the UV-vis spectra of the metal complexes with phenolic oximes provided a quick and unambiguous method of distinguishing between samples of nickel(II) and copper(II) species (example spectra are provided in the supporting information). In this activity we again found that the copper(II) complex exhibited a significant bathochromic shift $\left(\lambda_{\max }=354 \mathrm{~nm}\right)$ of the signal arising from $\mathrm{C}=\mathrm{N} \mathrm{n} \rightarrow \pi *$ transition relative to the free oxime ligand $\left(\lambda_{\max }=314 \mathrm{~nm}\right)$ and the Ni(II) complex $\left(\lambda_{\max }=308 \mathrm{~nm}\right)$ respectively. We found time constraints prevented the students from isolating and analysing the authentic nickel complex, 
copper complex and free oxime, as well as the copper complex they obtained from the $\mathrm{Ni}(\mathrm{II})$ and $\mathrm{Cu}(\mathrm{II})$ mixture. In this case, the students were provided with copies of authentic spectra and could therefore make a direct comparison of their own data with the example data sets. However, if more time is available to instructors, the option of isolating and analyzing of the authentic nickel complex and copper complex is straightforward. This option is accomplished by filtering the precipitates obtained from samples $\mathrm{C}$ and $\mathrm{D}$ shown in figure 2, the resulting solids can then be analysed by UV-visible spectroscopy (the relevant procedures are outlined in the supporting information).

\section{CONCLUSION}

A short and simple hydrometallurgy focused experiment has successfully been developed for use by senior high school students or $1^{\text {st }}$ year undergraduates. The simple tests described herein were found to be a quick and straightforward way to demonstrate selective binding of methoxyphenolic oxime 2 to $\mathrm{Cu}^{2+}$ in the presence of other transition metals in aqueous solution. The experiment has successfully been employed as part of a science summer school laboratory course that typically involves 20-30 students. Our findings were that this activity was successful in engaging the students and enabled them to formulate a simple hypothesis and select appropriate controls for the tests they conducted. In recent years, some excellent activities have been reported that demonstrate ligand selectivity for $\mathrm{Ni}^{2+}$ ions, ${ }^{10,11}$ we hope this experiment focused on $\mathrm{Cu}^{2+}$ will compliment these.

\section{ASSOCIATED CONTENT}

Supporting Information

An example laboratory manual entry and instructor notes, including relevant ${ }^{1} \mathrm{H}$ NMR spectra and UV-visible absorption spectra, have been provided (.DOCX and .PDF files). X-ray Crystallography data for copper complex $\mathbf{3}$ has also been provided (.CIF file) The Supporting Information is available on the ACS Publications website at DOI: 10.1021/acs.jchemed.XXXXXXX. [ACS will fill this in.]

\section{AUTHOR INFORMATION}

\section{Corresponding Author}

*Iain A. Smellie. E-mail: ias10@st-andrews.ac.uk 


\section{ACKNOWLEDGMENTS}

This experiment was developed and tested as part of the University of St Andrews CH4421 module and is now used as part of a University science summer school programme. The authors would like to thank Dr Siobhan Smith for acquisition of all the ${ }^{1} \mathrm{H}$ NMR spectra. Finally, the authors would also like to especially thank Professor Ross S. Forgan from the University of Glasgow for very fruitful discussions 10 years ago, these led to our earlier work and to many more interesting studies since.

\section{REFERENCES}

1. Smellie, I. A.; Forgan, R. S.; Brodie, C.; Gavine, J. S.; Harris L.; Houston, D.; Hoyland, A. D.; Miller, A. J.; Wilson, L.; Woodhall, F. M. Solvent extraction of copper: an extractive metallurgy for undergraduate laboratories. J. Chem. Educ., 2016, 93, 362-367.

2. Wilson, M. A.; Bailey, P. J.; Tasker, P. A.; Turkington, J. R.; Grant, R. A.; Love, J. B. Solvent extraction: the coordination chemistry behind extractive metallurgy. Chem. Soc. Rev., 2014, 43, 123-134.

3. Biefield, L. P.; Howe, D. E. Separation and determination of copper and nickel by salicylaldoxime. Ind. Eng. Chem. Anal. Ed., 1939, 11, 251-253.

4. Biefield, L. P.; Ligett, W. B.; Separation of copper, lead, and zinc with salicylaldoxime. Ind. Eng. Chem. Anal. Ed., 1942, 14, 359-361.

5. Simonsen, S. H.; Burnett H. M. Spectrophotometric determination of copper with salicylaldoxime. Anal. Ed., 1955, 27, 1336-1339.

6. Kadarmandalagi, S. G. Resacetophenone Oxime Chelation of Copper in the Presence of Cadmium. J. Chem. Educ. 1964, 41, 438.

7. Bühl, M.; Ashbrook, S. E.; Dawson, D. M.; Doyle, R. A.; Hrobárik, P.; Kaupp, M.; Smellie, I. A. Paramagnetic NMR of Phenolic Oxime Copper Complexes: A Joint Experimental and Density Functional Study. Chem. Eur. J., 2016, 22, 15328-15339.

8. Forgan, R. S.; Wood, P. A.; Campbell, J.; Henderson, D. K.; McAllister, F. E.; Parsons, S.; Pidcock, E.; Swart, R. M.; Tasker, P. A. Supramolecular chemistry in metal recovery; H-bond buttressing to tune extractant strength. Chem. Commun., 2007, 4940-4942.

9. Howe, D. E.; Mellon, M. G. Colorimetric determination of iron with salicylaldoxime. Ind. Eng. Chem. Anal. Ed., 1940, 12, 448-450.

10. Laird, D. W.; Henry, D. J. Is there Ni in my Liquor? A Hands-On Laboratory Exercise for Relating Chemistry to Extractive Metallurgy. J. Chem. Educ. 2013, 90, 1671-1674.

11. Tretiakov, A. Detection of Nickel Cations in Coins, Chemical Education Xchange (chemedx.org). https://www.chemedx.org/article/detection-nickel-cations-coins (accessed 31st January 2020) 
